\title{
ERNST BLOCH HOJE
}

Alysson Leandro Mascaro ${ }^{1}$

\section{Resumo:}

A filosofia de Ernst Bloch foi peculiar no tempo em que se desenvolveu. Muito por conta disso, é viva e capaz de enfrentar os problemas do presente. Este texto propõe ler a atualidade blochiana em cinco frentes: a) filosofia - Bloch não esteve enredado nas modas teóricas do século XX; b) marxismo - foi revolucionário, rigoroso e exigente com as lutas socialistas; c) política e direito - aponta para o fim do Estado e da forma jurídica; d) estética - sua posição de vanguarda se mantém; e) utopia - é combatido pelo realismo capitalista presente, que argumenta pela impossibilidade das alternativas, e também pelas postulações "éticas" que opõem a responsabilidade à utopia, mantendo os padrões da exploração capitalista, mas exatamente aí está a importância central da filosofia da esperança socialista ao presente.

Palavras-chave: Ernst Bloch. Utopia. Filosofia. Marxismo. Socialismo.

\section{ERNST BLOCH TODAY}

\begin{abstract}
:
During the time that it was developed, Ernst Bloch's philosophy was singular. That is because it is alive and able to face the present problems. This text proposes to demonstrate in five perspectives how actual Blochian thinking still is: a) philosophy - Bloch was not involved in the 20th century theoretical fashions; b) Marxism - it was revolutionary, rigorous and punctilious with socialist struggles; c) politics and law foresees the end of the State and the legal form; d) aesthetics - its position of vanguard remains; e) utopia - is opposed by the present capitalist realism, which argues for the impossibility of alternatives, and also by the "ethical" postulations that oppose responsibility to utopia, maintaining the standards of capitalist exploitation, but is in this exactly place that there is the core of the philosophy of socialist hope to the present.
\end{abstract}

Keywords: Ernst Bloch. Utopia. Philosophy. Marxism. Socialism.

A obra de Ernst Bloch caminha com frescor e não envelhece quando de sua chegada ao século XXI. Se é um típico filósofo do século XX, mais especificamente do conjunto das preocupações de sua primeira metade, Bloch é atual por um processo peculiar de afirmação filosófica: de um lado, pelos seus temas e preocupações, constituiuse de modo deslocado, recuado e diluído o suficiente para não se deixar contaminar com o específico e comezinho de seu tempo imediato; de outro lado, sempre foi radical nas apostas e nos posicionamentos do tempo, que paradoxalmente nem o tempo podia

1 Professor da Universidade de São Paulo (Faculdade de Direito do Largo São Francisco - USP). Advogado. Doutor e Livre-Docente em Filosofia e Teoria Geral do Direito pela USP. Autor, dentre outros livros, de "Utopia e direito: Ernst Bloch e a ontologia jurídica da utopia" (Ed. Quartier Latin) e "Filosofia do direito" (Ed. GEN-Atlas). E-mail: alysson@ mascaro.adv.br. 
entregar ou confirmar. Seu marxismo é também algo aristotélico, da melhor escatologia medieval, da bandeira tricolor revolucionária burguesa. Seu leninismo revolucionário é mais rigoroso e exigente eticamente que o dos leninistas e da prática soviética. A caminhada da filosofia de Ernst Bloch, assim, parece sempre politicamente anacrônica e, no mesmo diapasão, mais compromissada com o futuro almejado das lutas. É verdade que muitas vezes Bloch está engajado nas lutas do dia e fotografa o seu tempo como ninguém o fizera - sua obra sobre Weimar e o nazismo, Erbschaft dieser Zeit, é exemplar dessa visão. Mas, de modo concomitante a ter nas mãos as fotos do que todos também veem à frente, Bloch porta e manuseia as pinturas e desenhos do passado e, em especial, os projetos arquitetônicos do futuro, pelo qual se permite sempre apontar para o que se deve empreender de destruição/construção para o socialismo. Nunca é apenas o presente por ele próprio, dado que retorna sempre ao passado e se perspectiva ao futuro.

Tal movimento tanto de deslocamento com ares anacrônicos quanto de um lançamento radical ao futuro se confirma em todas as questões centrais do pensamento de Ernst Bloch, a destacar: $a$ ) sua própria filosofia; $b$ ) o marxismo; $c$ ) a política e o direito; d) a estética; e) a utopia. Filosoficamente, Bloch parece ser portador de um antigo humanismo, de feição caritativa ou quase espontânea, que a filosofia alemã, em outros paradigmas, também viu florescer em Friedrich Nietzsche, Walter Benjamin ou HansGeorg Gadamer, uma filosofia menos universitária ou analítica e mais calcada à realidade vivida; de outro lado, não está necessariamente preso aos modismos e balizas do século XX: não sofre o peso das âncoras oficiais do pensamento institucionalmente estabelecido, da filosofia analítica à virada linguística, nem tampouco do adesismo ao existencialismo e a outras vagas que depois sucumbiram, perecendo filosoficamente. Para as questões do marxismo, Bloch é menos ortodoxo que outros pensadores como György Lukács e, em comparação a este, também menos engajado nos termos do stalinismo; ao mesmo tempo, é mais apaixonadamente leninista, revolucionário das massas, ligado à classe trabalhadora. No que tange à política e ao direito, é contrário ao enrijecimento estatal e ao mundo normatizado e juridicizado; o poder popular e a justiça contra o direito são seus corolários. Esteticamente, não acompanhou as aventuras e desventuras do realismo socialista; seu expressionismo abraçou, com choque e incômodo, a vanguarda. Filósofo da utopia e da esperança, foi menos prático que os que viviam a luta do dia-a-dia; entretanto, quando chega o refluxo das revoluções e o antimarxismo, não se cansou nem se tornou conservador como os que viram na utopia o perigo e então, de modo contrário, 
passaram a advogar o "princípio responsabilidade". Tampouco naturalizou o capitalismo a ponto de considerar sua condição histórica insuperável. Bloch persevera apontando à esperança do futuro socialista.

\section{A filosofia de Bloch hoje}

O modo de consecução filosófica de Ernst Bloch - o estilo de pensamento, como alguns diriam atualmente - não é típico do século XX. Quando já a filosofia se profissionalizara e se tornara universitária, girando em torno de suas próprias referências e se tornando analítica, quase sempre limitada à leitura estrutural dos textos, Bloch, embora realizando monumentos de filosofia conceitual e sistemática, como Subjekt Objekt, Das Materialismusproblem, seine Geschichte und Substanz ou Experimentum Mundi: Frage, Kategorien des Herausbringens, Praxis, construía em especial uma filosofia aberta, sensibilizada pelos fragmentos e demandas da vida vivida, sem medo de proceder a totalizações, conclusões ou extrações de implicações práticas, políticas, éticas, mesmo morais. Não se pode dizer que esse posicionamento houvera sido frequente no passado e só no século XX se tornou anacrônico. Se se tomam pensamentos paradigmáticos como os de Hegel e Marx no século XIX, ou o de Kant no século XVIII, ver-se-á que uma filosofia mais caleidoscópica ou ensaística tem sido sempre exceção. No começo do século XIX, um Lamennais foi um filósofo mais de entusiasmo que de conceito; em um horizonte totalmente contrário, no final do mesmo século, Nietzsche é um modelo de filosofia de contraponto ao texto de talhe escorreito ou à dissertação autolimitada. No século XX, Benjamin, amigo de Bloch, é ainda mais um exemplo de afazer filosófico peculiar, que deixará marcas patentes, dentre outros, nos Spuren blochianos.

Também Bloch partilha de uma visão sobre a realidade que busca não colocar sobre ela a grade ou a planilha dos conceitos antes do vivido. Neste sentido, procede a uma valorização do efetivo, o que não quer dizer sagrá-lo ou apoiá-lo, mas, sim, fazer começar por ele a tarefa da crítica - apoiar-se no efetivo contra ele próprio. Com isso, Bloch não opera nos trâmites costumeiros da sociologia, estabelecendo categorias, proposições e deduções genéricas como as que poderiam considerar a classe trabalhadora, por desprovida dos meios de produção, revolucionária de pronto. Nem tampouco, em

\begin{tabular}{|c|c|c|c|c|}
\hline Q Rovita Dialectus & Ano 10 & n. 21 & Janeiro - Abril 2021 & p. $11-23$ \\
\hline
\end{tabular}


sentido contrário, poderia constatar que, sendo as massas alemãs fascistas, então não brotassem ali contradições que pudessem ser exploradas para a resistência e mesmo a revolução. A vida vivida pulsa mais dinâmica e mais contraditória que os conceitos gerais ou os rótulos que se tentam colocar sobre ela. Tal respeito à miséria, à fragilidade e à quotidianidade dos seres humanos, às suas relações sociais, seus valores, orientações, bloqueios e impulsos, faz de Bloch um pensador peculiar no século XX. Gadamer, na sua perspectiva hermenêutica, chamada de caritativa por observar com olhos respeitosos a sabedoria, as contradições e o modo de fazer do jurista, do teólogo, do leitor ou do médico, neste sentido se emparelha com Bloch ao não sobrepor, por antecipação, os guias filosóficos e conceituais àquela que é a existência em sua fluidez de preconceitos e dificuldades.

A fraqueza de Bloch - bem como a de Nietzsche ou de Benjamin - em face da filosofia mais conceitual, mais autorreferente, é também a causa de muito de seu frescor constante. Ao menos um grande eixo se estabeleceu na filosofia oficial, universitária, do século XX, engessando os padrões de pensamento teórico: a filosofia de feição analítica, que tem na linguagem seu esteio principal. Tipicamente anglo-saxã e estadunidense, com um poder de coerção quase automático nos centros intelectuais que emulam o capital e suas bases de financiamento, essa filosofia de confirmação das formas e padrões do capitalismo, se tem um chão de sucesso, tem um teto de constrangimento de possibilidades que a faz fenecer por não avançar contra as contradições do seu próprio tempo. Em face desse ambiente dominante, Bloch é sempre um golpe contra tais amarras filosóficas do mainstream.

Ao mesmo tempo, naqueles que não são os eixos oficiais do pensamento filosófico analítico e linguístico de língua inglesa, os eixos europeus continentais portanto, sucederam-se vagas filosóficas dominantes que, se não são limitadas como as do eixo dominante, são marcadamente presas aos tempos históricos nos quais ganharam projeção. Os existencialismos - desde a filosofia existencial de Heidegger até as visões francesas de Sartre ou Camus - impactaram grandemente setores do próprio marxismo, como partes do pensamento de Marcuse ou o caso de Lukács em sua última fase. Embora se possam estabelecer alguns pontos de diálogo, Bloch não embarca diretamente em uma perspectiva existencial ou existencialista. Seu anacronismo possibilitou que, também, não fosse tragado com o esgotamento dessa vaga. Leituras estruturalistas ou pósestruturalistas - das quais Bloch é insuspeito de proximidade -, contrastando com aquelas 
existencialistas, conseguem absorver o pensamento de Bloch com mais facilidade do que o fazem com Lukács e Marcuse. Algo da vitalidade de Bloch no presente vem, justamente, de sua filosofia que, girando em seus próprios temas e inquietações, atravessa modas ou coerções filosóficas oficiais como sendo quase que uma exótica, curiosa ou pitoresca contraposição ou composição.

\section{O marxismo de Bloch hoje}

Ernst Bloch se aproxima do marxismo após a primeira etapa de sua formação intelectual ter sido realizada com um doutorado sobre Heinrich Rickert e, também, partilhando de convivências e ambientes como os de Georg Simmel, Max Weber e Gustav Radbruch. Quando da Revolução Russa, Bloch, já na segunda edição de seu Geist der Utopie, em 1923, passa a dialogar diretamente com o marxismo. Toda sua trajetória, a partir daí, é marxista, seja no campo filosófico seja na vida pessoal. Após a Segunda Guerra Mundial, tendo se exilado nos EUA, escolhe voltar para a República Democrática

Alemã, a Alemanha Oriental, num movimento incomum entre outros intelectuais de esquerda alemães exilados ao tempo do nazismo.

O marxismo de Bloch sempre se assentou em bases peculiares, dados inclusive os temas que o moviam. A escatologia, a religião, a utopia, não eram, no século $\mathrm{XX}$, questões centrais do pensamento ou da luta política marxista. Por isso, historicamente, a desconfiança do campo soviético ou oficial dos partidos comunistas com as posições blochianas. Seu engajamento à causa comunista não se fazia acompanhar do mesmo modo à causa de alguns dos governos reputados comunistas. Quando se o compara à sua contraface marxista mais imediata, Lukács, percebem-se dois movimentos divergentes. No campo filosófico, a temática blochiana - única e constante - é persistentemente tangencial à do marxismo "ortodoxo", enquanto a lukacsiana - em suas variadas e distintas fases - busca sempre ser oficial: consciência de classe, classe trabalhadora como sujeito revolucionário, centralidade ontológica do trabalho. No campo político, ambos foram próximos do mundo soviético e em algum momento com ele contrastaram, mas Lukács é mais stalinista - vide sua posição de apoio ao realismo socialista - e também mais diretamente político, como em sua posição no governo húngaro de Imre Nagy, enquanto Bloch é mais profético, menos agente prático. Sempre

\begin{tabular}{|l|l|l|l|l|}
\hline Govista Dialectus & Ano 10 & n. 21 & Janeiro - Abril 2021 & p.11-23 \\
\hline
\end{tabular}


foi leninista, e isso não representou considerar todo o stalinismo como sequência imediata e necessária do leninismo. Sua posição leninista, entusiasmada, é revolucionária porque se funda numa disposição constante a superar o capitalismo, num processo que se pode iniciar sempre, podendo se incrementar do mesmo modo.

Ocorre que Bloch, menos alinhado aos governos socialistas oficiais do século XX, é mais marxista pelos objetivos do marxismo. Sua fixação teórica em torno da utopia o faz o maior especialista em projetar o que se almejava a uma sociedade socialista. Com isso, também menos se ocupava dos percalços do caminho - e das escolhas ora fracassadas, ora infelizes - do mundo soviético. Seu engajamento prático menor é também seu engajamento teórico e de horizontes maior. Sua própria contraposição a Lukács no que diz respeito ao realismo socialista é demonstração de que era mais rigoroso com os horizontes comunistas que os comunistas no poder soviético. Se a luta socialista era de vanguarda, Bloch nunca renunciou a ela. Ao tempo, estava em diapasão menos engajado na faina quotidiana que os vitoriosos. Mas, quando da derrocada de tais antigos vitoriosos, o pensamento de Bloch permaneceu consequente e vigoroso.

\section{A política e o direito de Bloch hoje}

Mergulhado no ambiente alemão da República de Weimar e do fracasso do SPD, Bloch percebe na ascensão do nazismo um apelo às massas trabalhadoras que as esquerdas e o marxismo não alcançavam. Em Erbschaft dieser Zeit, busca compreender as conexões culturais, religiosas, espirituais, entre os nazistas e as classes pobres. Às lutas socialistas, não bastava ser portadoras da verdade e da ciência: era preciso falar a linguagem do povo, tocar sentimentos, alcançar as múltiplas temporalidades que se sobrepunham em cada tempo histórico. Lutar pelo futuro era alcançar os passados que ainda reinavam e davam sentido às subjetividades. De algum modo - e ao seu modo -, Bloch antecipa os grandes problemas da ideologia e da subjetividade, que serão tratados com maior preocupação pelas reflexões contemporâneas do marxismo.

Em Naturrecht und menschliche Würde, escrito nos anos de Segunda Guerra Mundial e exílio nos EUA, Bloch avança pela compreensão da política em quadrantes muito próximos daqueles da tradição da filosofia marxista. Tal qual Engels, considera o Estado ligado à apropriação privada. Tal qual Lênin, também propugna que o Estado

\begin{tabular}{|c|c|c|c|c|}
\hline Q Rovista Dialectus & Ano 10 & n. 21 & Janeiro - Abril 2021 & p. $11-23$ \\
\hline
\end{tabular}


fenecerá no socialismo. Sua posição política é das genéricas fórmulas marxistas - Estado como comitê gestor da burguesia. No entanto, jamais resvala pela valorização do Estado burguês se democrático, como foi o caso em boa parte dos pensamentos socialdemocratas que tiveram originalmente bases marxistas, na segunda metade do século $\mathrm{XX}$ (vide o eurocomunismo ou a democracia como valor universal no Brasil). Bloch insiste no caráter transitório do fenômeno estatal, a ser vencido inexoravelmente pelas lutas socialistas. Com isso, quando surgirem as novas leituras marxistas sobre o Estado, mais rigorosas, científicas e consequentes, como aquelas do debate acerca da derivação do Estado, as proposições de Bloch, ainda que genéricas, não lhe são opostas, permitindo uma reapropriação. A utopia sobre o Estado é a extinção do Estado.

O mesmo padrão pode ser visto na leitura jurídica de Bloch, ainda em Naturrecht und menschliche Würde. Sua capacidade de vislumbrar uma crítica estrutural ao direito é ímpar ao seu tempo. É notável que seja Bloch o primeiro a redescobrir Pachukanis, pouco tempo após seu ocaso sob Stálin. Associando o fenômeno jurídico não a uma normatividade genérica, mas à forma mercantil, Pachukanis será o parâmetro de Bloch para considerar o horizonte socialista não como utopia de um novo direito, e sim como utopia da extinção do direito. Em seu lugar, Bloch aponta ao justo, à dignidade humana. O inventário que realizou da história do direito natural revela, em vários momentos, a luta dos de baixo como sentido do justo. $O$ futuro não será a administração social mediante bom direito, será a tomada do poder pelos próprios explorados. A leitura jurídica blochiana, ainda que dissolvida em águas de múltiplas fontes do justo e do digno, é radical na posição de que a forma do direito deverá ser extinta no socialismo.

Se o decurso do século XX foi todo mobilizado e sinalizado pela revolução socialista, as suas últimas décadas e o início do século XXI são marcados pelo impedimento da revolução. O capitalismo autorreputado triunfante, de feição neoliberal, reposiciona os termos da filosofia política. Habermas, que vinha de tradição marxista, rejeita os padrões revolucionários em favor do louvor da democracia liberal, do direito e de pretensos consensos. Bloch viveu antes do neoliberalismo, nos tempos do apogeu revolucionário. Morreu como entusiasta da transformação radical, desconhecendo as viradas linguísticas, a consagração da direita e o encurtamento dos horizontes políticos dos anos posteriores. Seu pensamento tem atravessado as décadas neoliberais a contrapelo, sem louvar Estado e direito como alternativas sociais. A apropriação 
blochiana, após sua morte, tem sido sempre pela esquerda. De modo patente e imaculado, não há qualquer proveito de Bloch ao neoliberalismo.

\section{A estética de Bloch hoje}

A estética permeou toda a reflexão de Bloch. Participou ativamente dos debates artísticos e das referências eruditas de seu tempo, em ambientes disputados diretamente pelo marxismo. Já no início de sua obra, em Geist der Utopie, tratava abundantemente de música, como a de Wagner. Mas na Alemanha dos tempos de Weimar, era o expressionismo que marcava a contundência crítica na arte. Bloch partilhava de tal ambiente, tendo sido amigo de boa parte de seus expoentes. Karola Bloch, a segunda de suas esposas, arquiteta, formou-se no ambiente da Neue Sachlichkeit, nova objetividade, embebido de expressionismo.

Peculiarmente, se a revolução russa liberou, nos primeiros anos da União Soviética, grandes energias estéticas de vanguarda, logo em seguida enrijeceu-se e converteu a arte aos propósitos de consolidação do poder estatal soviético. Inicia-se, então, um longo trajeto de afirmação do chamado realismo socialista. Calcado em uma estética de ortodoxia na representação artística, de mais fácil entendimento e aceitação pelas massas, o realismo socialista buscou se ligar diretamente às bases já consolidadas pela fruição estética da classe trabalhadora. Como resultado, movimentos artísticos de vanguarda foram combatidos e mesmo, em pouco tempo, sufocados.

Os horizontes do realismo socialista identificaram as posições oficiais, prósoviéticas, mais stalinistas que propriamente leninistas, dado a especial atenção de Stálin ao tema. No grande arco de artistas e filósofos que, pelos meados do século XX, produziram ou defenderam o realismo socialista, destacou-se Lukács. Louvando em literatura manifestações que ainda pudessem espelhar a realidade, com formas e narrativas classicistas, de feições canônicas, como as de Thomas Mann, Lukács vai se separando das posições blochianas, que estavam embebidas das experiências alemãs de vanguarda e às quais Lukács acusaria de decadentismo. $\mathrm{O}$ contraste marca o relativo atraso das posições estéticas de Lukács e a insistência blochiana no novo.

Também sua matriz expressionista fez com que Bloch se firmasse em princípios de vanguarda que não fossem meramente subjetivistas ou idealistas. O cansaço

\begin{tabular}{|c|c|c|c|c|}
\hline Q Rovita Dialectus & Ano 10 & n. 21 & Janeiro - Abril 2021 & p. $11-23$ \\
\hline
\end{tabular}


da estética contemporânea ou sua condição meramente performática, para a valorização mercantil, não eram escopos de sua petição estética. Se novas vanguardas surgiram após os anos iniciais da formulação do pensamento artístico de Bloch, elas foram menos radicais que as de seu tempo, de tal sorte que não se tratou jamais de tomar sua posição por conservadora ou arcaica: ele se manteve radical na orientação política que modulava, deformava, majorava e perspectivava a realidade para dela fazer o clamor social. Sua estética expressionista, moderna, da nova objetividade, mesmo tendo sido típica do início do século XX, vive.

\section{A utopia de Bloch hoje}

A utopia é o mais importante estandarte do pensamento de Ernst Bloch, o seu tema recorrente, a preocupação que atravessa todos os demais âmbitos de sua filosofia. Distinguindo-se das tantas visões sobre a utopia que existiram nos séculos anteriores místicas, religiosas, idealistas ou voluntaristas, num longo arco que passa pelos medievais até chegar ao socialismo utópico do século XIX - Bloch levanta o horizonte da utopia concreta, de que Das Prinzip Hoffnung é sua obra monumental. O possível concreto, sustentado tanto na objetividade quanto na ação subjetiva, erige o Noch-Nicht-Sein.

As utopias de perfil idealista e metafísico se desenvolveram em variadas épocas nas quais a revolução não se apresentava como paradigma. Mas, ao final do século XIX, a partir das lutas socialistas, a utopia se torna concreta, científica e possível. Logo em seguida, viu-se, em meio aos horrores de uma guerra mundial, o florescimento da União Soviética. Por isso, já no século XX, Bloch desenvolve toda sua filosofia da esperança em termos revolucionários, o que faz com que, em face do seu próprio tempo, o pensamento blochiano sobre a utopia apresente-se tanto como acoplamento quanto como projeção. No que diz respeito ao acoplamento, as revoluções socialistas permitiam vislumbrar concretamente a utopia e, neste sentido, Bloch opera em sintonia com o tempo revolucionário. De outro lado, no que tange à projeção, a insistência na utopia em tempos nos quais os primeiros Estados pós-lutas revolucionárias já surgiam demonstra que Bloch opera em relativo contraponto com o próprio tempo, apontando para as projeções utópicas necessárias que a União Soviética não lograva e que ainda deviam se cumprir. Com isso, nem se pode considerar a filosofia da utopia blochiana totalmente divergente das lutas

\begin{tabular}{|c|c|c|c|c|}
\hline Q Rovita Dialectus & Ano 10 & n. 21 & Janeiro - Abril 2021 & p. $11-23$ \\
\hline
\end{tabular}


concretas de seu tempo, nem tampouco totalmente contida nos termos da experiência revolucionária dada. Sua posição, relativamente deslocada e persistentemente radical nos propósitos, aqui se confirma. Em tempos de esperança revolucionária, a utopia de Bloch é tanto sincrônica quanto crítica.

Após os tempos da revolução soviética, muitas lutas que se insurgiam pelo decorrer do século XX no mundo encontraram em Bloch as referências de sua esperança. Dos religiosos da teologia da libertação - que beberam diretamente de Atheismus im Christentum e Thomas Müntzer als Theologe der Revolution - até chegar aos estudantes e à juventude do maio de 1968, passando por uma miríade de movimentos progressistas, o pensamento de Bloch foi paradigma para várias batalhas por um novo amanhã. Ocorre que, ao final do século XX, advêm os tempos conservadores. Quando da morte de Bloch, ao final da década de 1970, já o neoliberalismo se avistava. Em seguida, deu-se a derrocada do mundo soviético. A utopia e a esperança passaram a ser consideradas fracassadas, combatidas e abominadas. Nesse grande âmbito presente de hostilidade à esperança, proponho a existência de duas categorias de oposição à utopia de Bloch: por impossibilidade ou por ética.

A filosofia da utopia de Bloch se encontra, nas décadas finais do século XX e nas primeiras do século XXI, com o refluxo das lutas. A declaração de Francis Fukuyama sobre o fim da história - bradando a vitória do capitalismo e do liberalismo é simbólica dos tempos que não vislumbram a utopia e a mudança. Começa a pairar, então, no quadro da filosofia e da ideologia, constituindo as subjetividades presentes, a ideia de que não se consegue escapar dos termos do capitalismo. Com isso, dá-se uma crescente naturalização daquele que é um modo de produção histórico e bastante recente na humanidade. Proposições ideológicas liberais e neoliberais dominam o cenário intelectual: concorrência, competitividade, progresso pela indução dos mais fortes e capazes, meritocracia, mão invisível do mercado, lex mercatoria, individualismo, autoajuda. Tamanha é a naturalização do capitalismo que vários novos marxistas, alguns diretamente inspirados em Bloch, como Fredric Jameson, mas também Slavoj Žižek, apontam para a frase recorrente que diz ser mais fácil pensar o fim do mundo que o fim do capitalismo. Efetivamente, no imaginário social hodierno - em filmes, obras de arte, argumentos de debates políticos, de meios de comunicação ou de conversações intersubjetivas, materiais que foram de muito gosto também para a análise de Bloch -, não se delineia a hipótese de que o capitalismo seja superado. Esperam-se hecatombes 
nucleares, astronômicas, viróticas, sanitárias, mas não o socialismo. Já no início do século XXI, Mark Fisher, na mesma inspiração, demonstra que a fase atual do capitalismo achata qualquer possibilidade utópica: o horizonte ideológico dos tempos correntes é de realismo capitalista, em sua plena crueza, sem o vislumbrar de alternativas.

Mas, além do combate à utopia pelo argumento da impossibilidade de sua concretização, há também uma vertente de oposição a Bloch que não aceita os próprios termos da filosofia da utopia. Nesta contraface "progressista" do mesmo momento neoliberal, com ares similares aos de Hannah Arendt, argumenta-se que as revoluções foram sangrentas, violentas, que o comunismo tem características ditatoriais que sufocam as liberdades individuais, equipara-se socialismo a nazifascismo, de tal sorte que a utopia passa a ser considerada exatamente a projeção do que se deve evitar. Leituras como a do "princípio responsabilidade" de Hans Jonas, calcadas no respeito à ecologia e na contenção à tecnologia, acabam por ser, fundamentalmente, de combate à ação social e histórica transformadora. Ao associar socialismo às mazelas do desenvolvimentismo industrial, confundem-se fenômenos que, no século $\mathrm{XX}$, foram de matriz tipicamente capitalista, ainda que também tenham se dado no solo do segundo mundo, soviético, que buscava se modernizar em termos de atualização mercantil-produtiva em face do mesmo procedido pelo primeiro mundo. Um grande bloco, que não é neoliberal pela impossibilidade de que surja um novo, ao estilo Fukuyama e economistas de mercado, mas sim neoliberal por ética - porque o novo pode surgir e ele é indesejável - vai de Michel Foucault da fase do cuidado de si até as apropriações da crítica de Heidegger à tecnologia por pensadores como Peter Sloterdijk, tendo em Hans Jonas seu expoente máximo. Se Jürgen Habermas chegou a rotular Bloch de Schelling marxista, isso se deve à enorme utopia, "irresponsável" no melhor sentido que se possa ter do termo, da fusão incremental da humanidade com a natureza. Isso envolve extrair, da sociabilidade e do natural, o melhor que guardem em potência. A responsabilidade blochiana com a natureza é tanto respeitá-la e confirmá-la quanto melhorá-la, potencializá-la. Tal como, com os seres humanos, a responsabilidade é transformá-los. Corrigir e incrementar a natureza; nascerem, viverem e morrerem melhor os seres humanos.

Assim, em tal contexto, delineiam-se as duas oposições filosóficas do tempo presente a Bloch. Para os neoliberais de mercado, a utopia é um inexistente, uma impossibilidade - para estes, Bloch está morto. Para os neoliberais "éticos", a responsabilidade passa a ser a nêmesis da utopia - para estes, Bloch deve ser combatido. 
Mas, pelos inimigos e pela perseguição, vê-se a grandeza do perseguido. O realismo capitalista e a "ética" que sustenta as bases do mundo como está são a manutenção de um modo de produção e de sociabilidade de exploração. De um lado, dizer sobre a morte da utopia ofende à história. De outro lado, a responsabilidade, como oposta à utopia, é a conservação dos termos do presente, mas ofende a qualquer orientação à dignidade considerar que o capitalismo seja ético, tanto quanto se considere o feudalismo ou escravismo tenham sido éticos no passado. O pensamento de Bloch se mantém em frescor porque a utopia concreta é exatamente contraposta a dois graves desvios: o economicista, que toma o capitalismo como uma determinação social ahistórica; o politicista, que toma a ética num plano alheio ao modo de produção e à estrutura de sociabilidade que o capitalismo constitui.

Em tempos de refluxo das lutas, Bloch persiste sendo o principal índice de que só a utopia aponta à dignidade, que ainda não se tem e é um sentido factível à luta que se deve empreender. A única responsabilidade possível em face da sociabilidade capitalista presente é a "irresponsabilidade" revolucionária. O socialismo mais uma vez está morto e mais uma vez está para ser construído pelos que mal vivem. A utopia concreta se sustenta tanto nas contradições e crises do capital quanto na luta das massas e da classe trabalhadora que um dia poderá vingar. Bloch está vivo porque enquanto houver capitalismo há exploração e dominação e, daí, há luta e história: a revolução e o socialismo são sempre a possibilidade.

\section{Referências:}

A obra completa de Ernst Bloch foi publicada pela Suhrkamp Verlag, de Frankfurt, com edições em 1977 e 1985. Seguem seus livros referenciados neste artigo com o ano de sua publicação inicial:

BLOCH, Ernst. Atheismus im Christentum. Suhrkamp Verlag, Frankfurt am Main, 1968.

BLOCH, Ernst. Das Materialismusproblem, seine Geschichte und Substanz. Suhrkamp Verlag, Frankfurt am Main, 1972.

BLOCH, Ernst. Das Prinzip Hoffnung. Suhrkamp Verlag, Frankfurt am Main, 19541959.

BLOCH, Ernst. Erbschaft dieser Zeit. Suhrkamp Verlag, Frankfurt am Main,1935. 
Bloch, Ernst. Experimentum Mundi: Frage, Kategorien des Herausbringens, Praxis. Suhrkamp Verlag, Frankfurt am Main, 1975

BLOCH, Ernst. Geist der Utopie. Suhrkamp Verlag, Frankfurt am Main, 1918 ; 1923.

BLOCH, Ernst. Naturrecht und menschliche Würde. Suhrkamp Verlag, Frankfurt am Main, 1961.

BLOCH, Ernst. Spuren. Suhrkamp Verlag, Frankfurt am Main, 1930.

BLOCH, Ernst. Subjekt - Objekt. Erläuterungen zu Hegel. Suhrkamp Verlag, Frankfurt am Main,1949.

Bloch, Ernst. Thomas Müntzer als Theologe der Revolution. Suhrkamp Verlag, Frankfurt am Main, 1921.

\begin{tabular}{|l|l|l|l|l|}
\hline Rovista Dialectus & Ano 10 & n. 21 & Janeiro - Abril 2021 & p. 11-23
\end{tabular}

